\title{
Use of Diagnostic Injections to Evaluate Sacroiliac Joint Pain
}

\author{
MELISSA W. JUNG, MD, KURT SCHELLHAS, MD, BLAKE JOHNSON, MD \\ Center for Diagnostic Imaging, St Louis Park, Minnesota
}

\begin{abstract}
The sacroiliac joint is a complex, variable, and irregular structure, thought to be the source of $15 \%$ to $30 \%$ of low back, pelvic, and radicular pain. Several predisposing factors, including prior spinal surgery and particularly lumbar fusion, can contribute to joint inflammation and acceleration of joint degeneration. Evaluation of the sacroiliac joint as a pain generator using history and physical alone can prove difficult, because a number of other pathologies can have a similar presentation. Whereas a number of tests are used to examine the joint, no single test alone has proven validity. Imaging alone has also not been proven efficacious, particularly in nonspondyloarthropathy-mediated pain. Although no "gold standard" exists, diagnostic sacroiliac joint block has been shown to be a useful confirmatory tool in assessing sacroiliac (SI) joint-mediated pain. Sacroiliac joint injection with local anesthetic and steroids can be used as a possible therapeutic endeavor to manage pain and inflammation.
\end{abstract}

Other \& Special Categories

\section{ANATOMY AND BIOMECHANICS}

The SI joint is a C-shaped joint that connects the spine to the pelvis, aiding in transmission of forces to the lower extremities. It is a diarthrodial joint, considered to be synovial, although only the inferior third of the SI joint demonstrates characteristics similar to a traditional synovial joint, whereas the superior portion of the joint is closer to the cartilaginous articulation of a symphysis. ${ }^{1}$ Although its motion is complex, the 2 most common types of SI joint movement are nutation and counternutation: flexion or extension of the sacrum with counterrotation of the ilium. The degree of rotation is small, ${ }^{2}$ only up to $4^{\circ}$. Whereas the exact pattern of innervation of the joint is unclear, studies have shown the presence of both periarticular and intraarticular nociceptive elements, supporting the view that the central nervous system receives painful stimuli from the joint. ${ }^{3-5}$

\section{PATHOPHYSIOLOGY}

Low back pain is extremely common, affecting an estimated $70 \%$ of people during their lifetime. ${ }^{6}$ The estimated rates of low back pain attributable to the SI joint is between $15 \%$ and $30 \%{ }^{7,8}$ The proposed mechanism of injury to the SI joint is likely a combination of axial loading and rotation. The etiologies of SI joint-mediated pain include intra- articular pathology such as arthritis and spondyloarthropathy as well as extra-articular pathology such as ligamentous or muscular injury or enthesopathy. Factors predisposing patients to SI jointmediated pain include leg-length discrepancy, transitional anatomy, scoliosis, persistent strain or low grade trauma, pregnancy, and spine surgery. ${ }^{9}$ Increased stress across the SI joint has been demonstrated by Ivanov et $\mathrm{al}^{10}$ using simulated surgical methods and is supported by computed tomography (CT) imaging evidence of accelerated SI joint degeneration in patients undergoing lumbosacral fusion when compared with matched controls. ${ }^{11}$

\section{PHYSICAL EXAMINATION}

Due to the overlapping pain patterns among the lumbar spine, SI, and hip joints, it is often difficult to clinically differentiate these pathologies. Fortin's mapping of SI joint pain pattern in asymptomatic individuals using diagnostic injection demonstrated an area within the buttock measuring $10 \mathrm{~cm}$ inferior and $3 \mathrm{~cm}$ lateral to the posterior superior iliac spine, ${ }^{12}$ but this area is also common to pain originating from the lumbar spine. No single physical exam technique or test has been shown to accurately identify SI joint pain. A thorough examination should include evaluation of the 
lumbar spine and hip as potential sources of pain. There are a number of maneuvers used to evaluate SI joint pain including the FABER (flexion, abduction, and external rotation), thigh thrust, pelvic distraction, pelvic compression, and pelvic torsion (Gaenslen) tests. Although no single test alone is specific for SI joint-mediated pain, if 3 of the 5 tests are positive, there is an $85 \%$ pretest probability of a positive diagnostic injection. ${ }^{13}$

\section{IMAGING}

In contrast to lumbar spine or hip imaging, specific imaging of the SI joint has not been shown to be efficacious in accurately correlating with SI jointmediated pain. Computed tomography of the SI joint, often used to evaluate the degenerative changes, has been shown to have a sensitivity of $57.5 \%$ and specificity of $69 \%$ in patients with SI joint-mediated pain. ${ }^{14}$ Radionuclide imaging has higher specificity rates but low sensitivity. ${ }^{15,16}$ Magnetic resonance imaging (MRI), although 90\% sensitive for evaluating sacroiliitis in spondyloarthropathies, is not as sensitive in evaluating the symptomatic nonspondyloarthritic SI joint. ${ }^{17}$ In addition, degenerative changes can often be seen in asymptomatic individuals, and SI joints proven to be inflamed and symptomatic with blockade often appear normal on imaging studies. Computed tomography and MRI are beneficial in excluding other causes, such as malignancy, infection, and fracture.

\section{DIAGNOSTIC INJECTION}

Whereas there is no true "gold standard" for SI joint-mediated pain, many clinicians use imageguided intra-articular blockade with local anesthetic to exclude or confirm clinically suspected SI joint symptomatology because it is target specific. The injections can be performed using fluoroscopy, CT, and even MRI or ultrasound. Sacroiliac joint injections without image guidance, also known as "blind" injections, are not recommended because studies demonstrated that intra-articular injection of the joint occurred in only $22 \%$ of these patients, with epidural or dorsal sacral foraminal flow demonstrated $24 \%$ and $44 \%$ of the time, respectively. ${ }^{18}$

The technique for injection with fluoroscopic guidance is as follows:

After informed consent, the patient is placed in the prone position. Using fluoroscopic guidance the SI joint is identified and the inferior corner of the

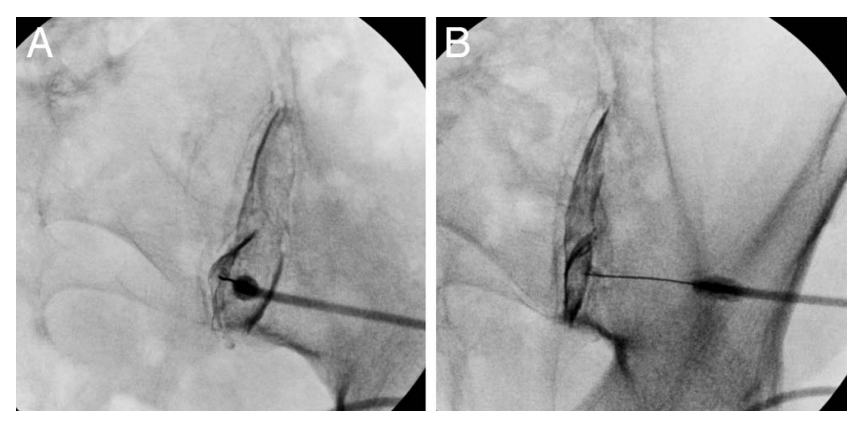

Figure 1. Sacroiliac joint arthrography. Two fluoroscopic views following the injection of $0.6 \mathrm{~mL}$ iohexol $240 \mathrm{mg} / \mathrm{mL}$ into the right sacroiliac joint clearly outlining the joint space.

joint, where we have found the joint to be most accessible to needle placement, is marked under the fluoroscopy. The area is sterilely prepped and draped. The skin may or may not be anesthetized with local anesthetic. The inferior third of the joint is accessed using a small-gauge (22- or 25-gauge) spinal needle. Intra-articular confirmation is performed via injection of a small amount of iodinated contrast under direct live fluoroscopy (Figure 1). Local anesthetic, with or without anti-inflammatory steroid, is then injected into the joint. The SI joint, though having a surface area of $17.5 \mathrm{~cm}^{2}$, has a small capacity ranging from 0.8 to $2.5 \mathrm{~mL}$ in asymptomatic individuals and 1.0 to $2.7 \mathrm{~mL}$ in symptomatic individuals. ${ }^{19,20}$ It is generally advised $^{21}$ not to inject a total volume greater than $2.5 \mathrm{~mL}$, because extravasation from the joint can leak onto nearby neural structures and compromise the target specificity of the injection. It is common to provoke a mild pain sensation during the therapeutic injection. This can be assessed regarding concordant or nonconcordant relation to the clinical pain being investigated. Fluoroscopy is most commonly used due to availability and cost, but the same procedure can be performed under CT (Figure 2 ), particularly if one is unable to access the joint via fluoroscopy due to the presence of dorsal marginal osteophytes (Figure 3). Injection under MRI or ultrasound could be considered, particularly if the injection must be performed in a pregnant individual. Regardless of imaging modality, there should be documentation that the injection is intra-articular.

It is recommended that patients refrain from taking pain medication the day of the injection to aid in accuracy of diagnostic response to injection. A preinjection level of pain should be obtained to accurately determine patient response. Postinjec- 


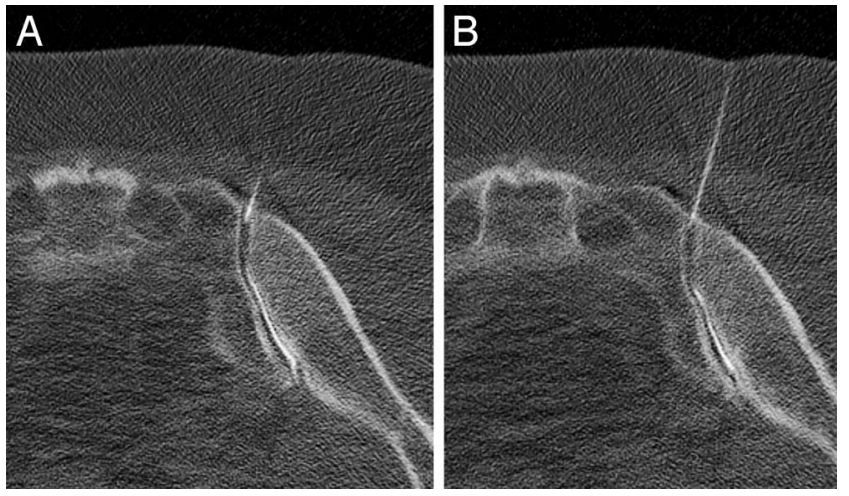

Figure 2. Computed tomography-guided sacroiliac joint arthrography. Sequential axial images of the right sacroiliac joint, following injection of 0.5 $\mathrm{mL}$ iohexol $240 \mathrm{mg} / \mathrm{mL}$, demonstrating the needle tip within the joint and clear intra-articular opacification.

tion, if there are provocative activities associated with the patient's pain, having the individual engage in such activities prior to and after the injection can also aid in diagnosis.

Local anesthetic works by blocking sodium channels, and the length of relief should correlate
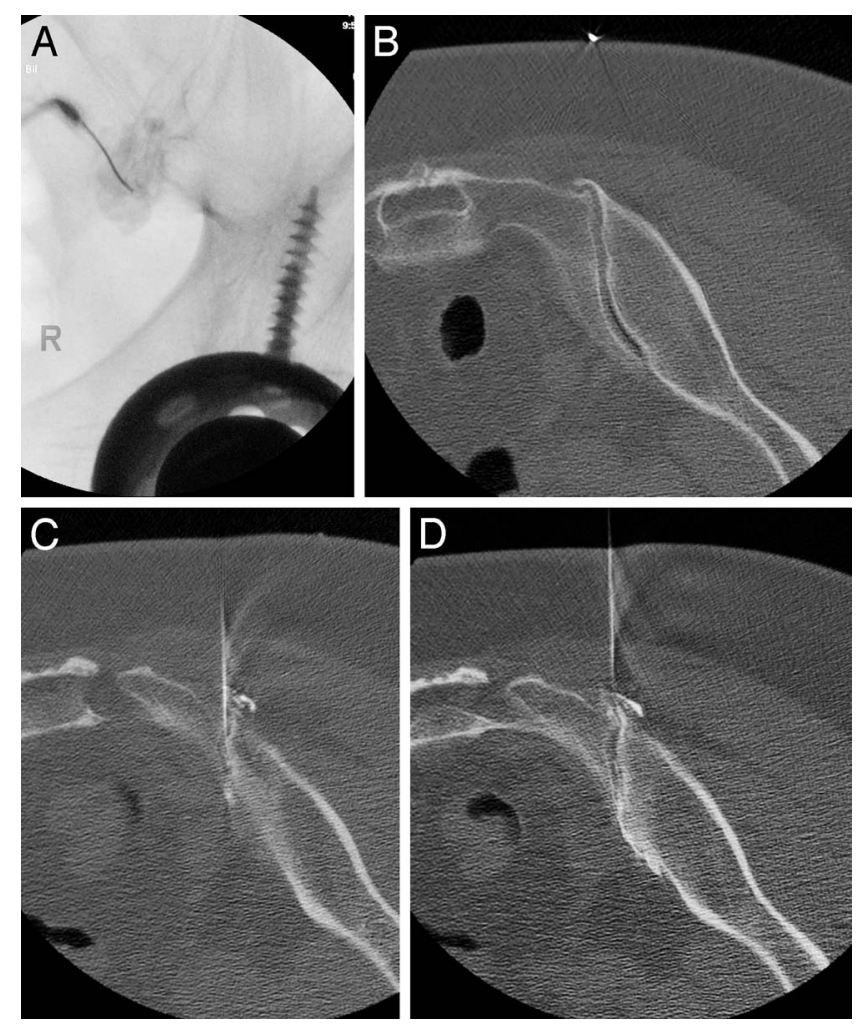

Figure 3. Fluoroscopic versus computed tomography (CT)-guided sacroiliac (SI) joint injection. (A) Fluoroscopic attempt at right SI joint injection, demonstrating predominantly periarticular contrast opacification. The same patient $(\mathrm{B})$ demonstrating a medially oriented osteophyte on preinjection $\mathrm{CT}$ images and (C-D) postinjection images demonstrating intra-articular opacification of the joint. with the duration of anesthetic activity. In an ideal situation, the patient would undergo injection of a control agent, such as saline, to mitigate for false positives. However, this would require informed consent, and many patients may object to undergoing a sham procedure. An alternative to placebo control is use of a confirmatory or double block, where the patient undergoes 2 diagnostic injections using 2 different local anesthetic agents. Generally, the first block is performed with a shorter-acting anesthetic, such as lidocaine, whereas a longer-acting anesthetic, bupivacaine, is used for the confirmatory block. The duration of effect for lidocaine is about 0.5 to 3 hours versus bupivacaine, which is 2 to 5 hours. ${ }^{22}$ A pain diary may also be helpful in recording the patient's response and in correlating to the particular anesthetic.

The degree of pain relief required for a confirmatory response and to predict clinical outcome is unclear. Most studies and pain management societies have used a criterion of at least $75 \%$ relief from local anesthetic, as diagnostic. ${ }^{23-25}$ However, a recent study demonstrated good response to SI joint fusion in patients with $50 \%$ relief from diagnostic SI joint block, suggesting that those patients with a $50 \%$ to $74 \%$ response to diagnostic block may still benefit from certain treatments. ${ }^{26}$ One of the reasons suggested for this is that SI joint fusion acts as a mechanical stabilizer, possibly affecting both the intra-articular and extra-articular structures, whereas the anesthetic works biochemically, blocking the nerves innervating the articular surface. This may also explain why some studies suggest potential benefit with both intra-articular and periarticular injection of corticosteroid. ${ }^{27,28}$ Injection of corticosteroid can have both a diagnostic and potential therapeutic benefit. Patients who undergo SI joint injections of both local anesthetic and corticosteroid should have a biphasic response: immediate from the anesthetic and delayed from the steroid. If steroid is administered, patients should be asked to keep a pain diary and monitor their pain level on a daily basis for at least 1 week.

\section{SUMMARY}

The SI joint is a complex and important biomechanical structure that is richly innervated and can serve as a pain generator. Whereas acceptance of the SI joint as a potential source of 
low back pain has grown, confirming that it is the cause of a patient's pain remains a diagnostic challenge. This reflects a combination of factors including the inherent anatomical and biomechanical complexity of the joint, as well as its overlapping clinical presentation with adjacent structures. Although a thorough and complete physical examination is essential in evaluation of the sacroiliac joint, no noninvasive pathognomonic test exists to reliably differentiate it from other potential pain generators. Fluoroscopic or CT-guided blockade can serve as a reliable and confirmatory diagnostic tool to aid in the evaluation of SI joint-mediated pain.

\section{REFERENCES}

1. Puhakka KB, Melsen F, Jurik AG, Boel LW, Vesterby A, Egund N. MR imaging of the normal sacroiliac joint with correlation to histology. Skeletal Radiol. 2004;33(1):15-28. https://doi.org/10.1007/s00256-003-0691-4

2. Vleeming A, Van Wingerden JP, Dijkstra PF, Stoeckart $\mathrm{R}$, Snijders CJ, Stijnen T. Mobility in the sacroiliac joints in the elderly: a kinematic and radiological study. Clin Biomech. 1992;7(3):170-176. https://doi.org/10.1016/0268-0033(92)90032-Y

3. Roberts SL, Burnham RS, Ravichandiran K, Agur AM, Loh EY. Cadaveric study of sacroiliac joint innervation: implications for diagnostic blocks and radiofrequency ablation. Reg Anesth Pain Med. 2014;39(6):456-464. https://doi.org/10. 1097/AAP.0000000000000156

4. Szadek KM, Hoogland PVJM, Zuurmond WWA, De Lange JJ, Perez RSGM. Possible nociceptive structures in the sacroiliac joint cartilage: an immunohistochemical study. Clin Anat. 2010;23(2):192-198. https://doi.org/10.1002/ca.20908

5. Vilensky JA, O'Connor BL, Fortin JD, et al. Histologic analysis of neural elements in the human sacroiliac joint. Spine (Phila Pa 1976). 2002;27(11):1202-1207. https://journals.lww. $\mathrm{com} /$ spinejournal/pages/articleviewer aspx?year=2002\&issue $=$ 06010\&article=00012\&type $=$ abstract. Accessed January 30, 2020.

6. Andersson GB. Epidemiological features of chronic lowback pain. Lancet. 1999;354(9178):581-585. https://doi.org/10. 1016/S0140-6736(99)01312-4

7. Maigne JY, Aivaliklis A, Pfefer F. Results of sacroiliac joint double block and value of sacroiliac pain provocation tests in 54 patients with low back pain. Spine (Phila Pa 1976). 1996;21(16):1889-1992.

8. Schwarzer AC, Aprill CN, Bogduk N. The sacroiliac joint in chronic low back pain. Spine (Phila Pa 1976). 1995;20(1):3137. https://doi.org/10.1097/00007632-199501000-00007

9. Cohen SP, Chen Y, Neufeld NJ. Sacroiliac joint pain: a comprehensive review of epidemiology, diagnosis, and treatment. Expert Rev Neurother. 2013;13(1):99-116. https://doi.org/ 10.1586/ern.12.148

10. Ivanov AA, Kiapour A, Ebraheim NA, Goel V. Lumbar fusion leads to increases in angular motion and stress across sacroiliac joint: a finite element study. Spine (Phila Pa
1976). 2009;34(5):E162-E169. https://doi.org/10.1097/BRS. 0b013e3181978ea3

11. Ha K-Y, Lee J-S, Kim K-W. Degeneration of sacroiliac joint after instrumented lumbar or lumbosacral fusion: a prospective cohort study over five-year follow-up. Spine (Phila Pa 1976). 2008;33(11):1192-1198. https://doi. org/10.1097/BRS.0b013e318170fd35

12. Fortin JD, Dwyer AP, West SPJ. Sacroiliac joint: pain referral maps upon applying a new injection/arthrography technique. Spine (Phila Pa 1976). 1994;19:1475-1482.

13. Laslett $\mathrm{M}$, Aprill CN, McDonald B, Young SB. Diagnosis of sacroiliac joint pain: validity of individual provocation tests and composites of tests. Man Ther. 2005;10(3):207-218. https://doi.org/10.1016/j.math.2005.01.003

14. Elgafy H, Semaan HB, Ebraheim NA, Coombs RJ. Computed tomography findings in patients with sacroiliac pain. Clin Orthop Relat Res. 2001;382:112-118. https://doi.org/10. 1097/00003086-200101000-00017

15. Slipman CW, Sterenfeld EB, Chou LH, Herzog R, Vresilovic E. The value of radionuclide imaging in the diagnosis of sacroiliac joint syndrome. Spine (Phila Pa 1976). 1996;21(19):2251-2254. https://journals.lww.com/spinejournal/ pages/articleviewer.aspx?year=1996\&issue=10010\&article= 00013\&type=abstract. Accessed January 30, 2020.

16. Maigne JY, Boulahdour H, Chatellier G. Value of quantitative radionuclide bone scanning in the diagnosis of sacroiliac joint syndrome in 32 patients with low back pain. Eur Spine J. 1998;7(4):328-331. https://doi.org/10.1007/s005860050083

17. Puhakka K, Jurik A, Schiøttz-Christensen B, et al. MRI abnormalities of sacroiliac joints in early spondylarthropathy: a 1-year follow-up study. Scand J Rheumatol. 2004;33(5):332-338. https://doi.org/10.1080/03009740410005881

18. Rosenberg JM, Quint TJ, de Rosayro AM. Computerized tomographic localization of clinically-guided sacroiliac joint injections. Clin J Pain. 2000;16(1):18-21. https://journals. lww.com/clinicalpain/pages/articleviewer.aspx?year=2000\&issue= 03000\&article $=00004 \&$ type $=$ abstract. Accessed January 30, 2020.

19. Fortin JD, Dwyer AP, West S, Pier J. Sacroiliac joint: pain referral maps upon applying a new injection/arthrography technique. Part I: asymptomatic volunteers. Spine (Phila Pa 1976). 1994;19(13):1475-1482. https://journals.lww.com/spine journal/Abstract/1994/07000/Sacroiliac_Joint_Pain_Referral_ Maps_Upon_Applying.10.aspx. Accessed January 30, 2020.

20. Fortin JD, Aprill CN, Ponthieux B, Pier J. Sacroiliac joint: pain referral maps upon applying a new injection/ arthrography technique. Part II: clinical evaluation. Spine (Phila Pa 1976). 1994;19(13):1483-1489. https://journals.lww. com/spinejournal/Abstract/1994/07000/Sacroiliac_Joint__ Pain_Referral_Maps_Upon_Applying.11.aspx. Accessed January 30, 2020.

21. Kennedy DJ, Engel A, Kreiner DS, Nampiaparampil D, Duszynski B, Macvicar J. Fluoroscopically guided diagnostic and therapeutic intra-articular sacroiliac joint injections: a systematic review. Pain Med. 2015;16(8):1500-1518. https://doi.org/10.1111/ pme. 12833

22. Dreyer S. Commonly used medications in pain procedures. In: Lennard TA, ed. Pain Procedures in Clinical Practice. 2nd ed. Philadelphia: Hanley \& Belfus; 2000:1-9.

23. June CR, Aprill C, Bogduk N, et al. Educational guidelines for interventional spinal procedures. 2008;(June 2001). 
24. Rosenquist RW, Benzon HT, Connis RT, et al. Practice guidelines for chronic pain management: an updated report by the American Society of Anesthesiologists Task Force on Chronic Pain Management and the American Society of Regional Anesthesia and Pain Management. Anesthesiology. 2010;112(4):810-833. https://doi.org/10. 1097/ALN.0b013e3181c43103

25. Manchikanti L, Abdi S, Atluri S, et al. An update of comprehensive evidence-based guidelines for interventional techniques in chronic spinal pain. Part II: guidance and recommendations. Pain Physician. 2013;16(suppl 2):S49-S283. https://www.painphysicianjournal.com/linkout?issn=15333159\&vol=16\&page=S49. Accessed January 30, 2020.

26. Polly D, Cher D, Whang P, Frank C, Sembrano J. Does level of response to SI joint block predict response to SI joint fusion? Int J Spine Surg. 2016;10:4. https://doi.org/10.14444/ 3004

27. Luukkainen RK, Wennerstrand PV, Kautiainen HH, Sanila MT, Asikainen EL. Efficacy of periarticular corticosteroid treatment of the sacroiliac joint in non-spondylarthropathic patients with chronic low back pain in the region of the sacroiliac joint. Clin Exp Rheumatol. 2002;20(1):52-54.

28. Nacey NC, Patrie JT, Fox MG. Fluoroscopically guided sacroiliac joint injections: comparison of the effects of intra- articular and periarticular injections on immediate and shortterm pain relief. Am J Roentgenol. 2016;207(5):1055-1061. https://doi.org/10.2214/AJR.15.15779

Disclosures and COI: The authors received no funding for the study and report no conflicts of interest.

Corresponding Author: Melissa W. Jung, MD, Center for Diagnostic Imaging, 5775 Wayzata Blvd, Suite 190, St Louis Park, MN 55416. Phone: (952) 738-4456; Fax: (952) 738-7738; Email: melissa. jung@cdirad.com.

Published 10 February 2020

This manuscript is generously published free of charge by ISASS, the International Society for the Advancement of Spine Surgery. Copyright (C) 2020 ISASS. To see more or order reprints or permissions, see http://ijssurgery.com. 